\title{
Does the timing of surgery affect short-term prognosis in newborn infants with meningomyelocele?
}

Mustafa Kurthan Mert ( $\nabla$ kurthanmert@gmail.com )

University of Health Science Adana City Training and Research Hospital https://orcid.org/0000-00022789-2710

Ali İhsan Ökten

Adana City Training and Research Hospital

\section{Research}

Keywords: meningomyelocele, newborn, surgery time, prognosis

Posted Date: May 11th, 2020

DOl: https://doi.org/10.21203/rs.3.rs-27023/v1

License: (c) (i) This work is licensed under a Creative Commons Attribution 4.0 International License.

Read Full License 


\section{Abstract}

Objective: To investigate the effect of postnatal primary repair surgery time on short-term (first 30 days) prognosis in neonates with meningomyelocele (MMC).

Methods: The records of meningomyelocele patients treated at Adana City Training and Research Hospital between June 30, 2015 and August 1, 2019 were retrospectively reviewed. Demographic and clinical characteristics, surgical time, hospitalization and antibiotic duration, complications and associated anomalies were recorded.

Results: Data of 41 patients were evaluated. The patients were divided into two groups according to the time of surgery. There were 18 patients in the early surgery ( $\leq 3$ days) group and 23 patients in the late surgery ( $>3$ days) group. There was no difference between groups in terms of birth weight, gestational week, head circumference, sex and type of delivery ( $p>0.05$ ). The length of hospitalization was $17.2 \pm 8.2$ in the early surgery group and $24.8 \pm 16.1$ in the late surgery group $(p>0.05)$. Antibiotic duration was 11.8 \pm 7.6 in the early surgery group and $13.8 \pm 10.1$ in the late surgery group $(p>0.05)$. There was no difference between the two groups between the average size of the MMC sac $(5.4 \pm 1.1$ vs $6.1 \pm 2.3$, $p>0.05)$. The number of patients with postoperative complications in early surgery group was 8 (44.4\%) and in late surgery group was 7 (30.4\%), and the number of patients reoperated in the first 30 days in early surgery group was $5(27.7 \%)$ and in late surgery group was $6(26.1 \%)$. The number of patients requiring ventriculoperitoneal shunt (VPS) was 9 (50\%) in the early surgery group and 13 (56.5\%) in the late surgery group. Surgical complications minor-major dehiscences, CSF leakage, local infection, meningitis and ventriculitis are not statistically different between the groups $(p>0.05)$.

Conclusion: Although postnatal early surgical intervention in MMC positively affects short-term outcomes, short-term prognosis is also determined by the presence of associated anomalies, VPS placement time, and rupture of the sac.

\section{Introduction}

Among the congenital anomalies of the central nervous system, neural tube defects (NTD) are the most common. The most common form is meningomyelocele (MMC), which is characterized by extrusion of the spinal cord into a sac filled with cerebrospinal fluid. Meningomyelocele develops in the first 26 days of pregnancy due to a posterior closure defect of the neural canal [1]. MMC is a clinical condition that may cause lifelong symptoms such as disability and absence of sensation in the lower limbs, intestinal and bladder function disorders, varying degrees of mental retardation, depending on the size of the defect, the level of injury to the spinal cord, and associated anomalies [2].

Although its frequency has decreased with the application of periconceptional folate treatment in developed countries, it is still the most common congenital anomaly [3,4]. Prevalence in America is 3.4 per 10,000 births [4]. Although the incidence of MMC in developed countries is decreasing, its frequency 
also varies according to socioeconomic status, geographical region and race [6]. The incidence of neural tube defects seen in Turkey is significantly higher, with 3 to 9 per 1,000 live births $[7,8]$.

In addition to genetic factors, low socioeconomic status, alcohol use during pregnancy, isotretinoin, radiation exposure, antiepileptic (valproate and carbamazepine) medication use in pregnancy, hyperthermia, malnutrition, maternal folic acid, methionine, zinc and selenium deficiency are thought to play a role in NTD formation [6,9-12]. The most important risk factor identified in NTDs is folic acid deficiency. Preconceptional replacement of folic acid with $0.4 \mathrm{mg} /$ day reduces NTD formation by $60-70 \%$ [10].

Although there are many studies on the timing of surgical repair of meningomyelocele, especially with the introduction of intrauterine surgery, the number of studies to prevent morbidity is still limited. The aim of this study was to evaluate the effect of timing of MMC surgery on short-term prognosis and to evaluate the frequency of demographic and clinical features and associated anomalies.

\section{Material-method}

This study was conducted retrospectively in Adana City Training and Research Hospital with the approval of the local ethics committee. The medical records of the newborns diagnosed with MMC between June 30, 2015 and August 1, 2019 in the first 30 days of the postnatal period were systematically examined and demographic data, physical examination findings, congenital anomalies (hydrocephalus, Chiari 2 malformation, pes equinovarus, renal anomalies, VSD, scoliosis), defect size and localization data were recorded. Duration of hospital stay, antibiotic use, operation time, surgical and/or disease-related complications (wound infection, dehiscence, CSF leak, ventriculitis-meningitis, shunt infection, convulsion) were recorded. Echocardiography and abdominal-renal USG were performed preoperatively in order to identify additional anomalies in all patients. In the preoperative period, the patients were evaluated with clinical findings and cranial USG for hydrocephalus. Cerebral CT was performed in patients with ventricular enlargement on cranial ultrasound. In cerebral CT, temporal horns larger than 2 $\mathrm{mm}$, obliteration in cerebral sulcus and fissures, expansion of frontal horns and third ventricle were accepted as hydrocephalus. After the meningomyelocele operation, the patients were followed up for vomiting, growth around the head, bradycardia and increased intracranial pressure findings such as the sun-setting sign.

VP shunting was performed due to the width of the head circumference, clinical findings of intracranial pressure increase, and the presence of proven hydrocephalus on cranial USG and CT. If the MMC area was large, intravenous antibiotic prophylaxis was administered to all patients 30 minutes before surgery and 72 hours postoperatively. The patients who were operated on in the first 3 days of the postnatal period were determined as early surgery group and the patients who were operated after 3 days as the late surgery group.

\section{Statistical analysis:}


SPSS 19.0 (SPSS Inc., Chicago, IL, USA) was used for data analysis. Categorical variables were summarized using counts and percentages, whereas continuous variables were summarized in mean \pm standard deviation values. The Student's t-test was performed to compare the means of the two groups. For non-normally distributed variables, the Mann-Whitney test was performed. A p-value less than 0.05 was accepted as statistically significant.

\section{Results}

Medical records of 41 patients with meningomyelocele who underwent surgery were collected in our clinic. Clinical and demographic data of the patients are summarized in Table 1. There was no statistical difference between the groups in terms of birth weight, gestational week, sex and head circumference measurements. The number of patients diagnosed with antenatal meningomyelocele was significantly higher in the early surgery ( $<3$ days) group ( 7 vs $2, p<0.05$ ). There was no difference in terms of hospitalization time (17.2 \pm 8.2 vs $24.8 \pm 16.1, p>0.05)$ and duration of antibiotic use (11.8 \pm 7.6 vs 13.8 $\pm 10.1, p>0.05)$ (Table 1).

Table 1. Demographic characteristics, clinical features and treatment periods of MMC patients

\begin{tabular}{lll} 
& $\begin{array}{l}\text { Early } \\
(\mathbf{n = 1 8})\end{array}$ & $\begin{array}{l}\text { Late } \\
(\mathbf{n}=\mathbf{2 3})\end{array}$ \\
\hline Birth weight, $\mathbf{g}$ & $3251 \pm 528$ & $3249 \pm 417$ \\
\hline Gestational weeks & $38.3 \pm 1.4$ & $38.2 \pm 2.0$ \\
\hline Head circumference, cm & $37.5 \pm 2.8$ & $37.0 \pm 2.4$ \\
\hline CS & $16(88.9 \%)$ & $15(65.2 \%)$ \\
\hline Female & $11(61.1 \%)$ & $10(43.5 \%)$ \\
\hline Syrian Refugee & $4(22.2 \%)$ & $8(34.8 \%)$ \\
\hline Antenatal Diagnosis & $7(38.9 \%)$ & $2(8.7 \%) *$ \\
\hline Apgar 5. min & $9.0 \pm 1.0$ & $9.0 \pm 0.7$ \\
\hline Hospitalization duration & $17.2 \pm 8.2$ & $24.8 \pm 16.1$ \\
\hline Antibiotic treatment duration & $11.8 \pm 7.6$ & $13.8 \pm 10.1$ \\
\hline *p<0.05 & &
\end{tabular}

CS Cesarian sectio 
The defect size was higher in the late surgery group between the two groups, but this difference was not statistically significant $(5.4 \pm 1.1$ vs $6.1 \pm 2.3, p>0.05)$ (Table 2$)$. Flap closure was performed by the plastic surgery department because direct closure could not be performed in 5 patients. VP shunt was placed in 22 patients. In 13 (31.7\%) patients, VP shunt was placed concurrently with MMC surgical repair, while VP shunt was placed later in $9(22 \%)$ patients. One or more complications due to surgery occurred in 15 (36.6\%) patients (Table 2).

\section{Table 2. MMC defect size and surgical data}

\begin{tabular}{lll} 
& $\begin{array}{l}\text { Early } \\
(\mathbf{n}=18)\end{array}$ & $\begin{array}{l}\text { Late } \\
(\mathbf{n}=23)\end{array}$ \\
\hline Defect size & $5.4 \pm 1.1$ & $6.1 \pm 2.3$ \\
\hline Defect size $>\mathbf{5} \mathbf{~ c m}$ & $9(50.0 \%)$ & $16(69.6 \%)$ \\
\hline Patients with associated anomalies & $11(61.1 \%)$ & $16(69.6 \%)$ \\
\hline Surgical procedure & & \\
Direct closure & $17(94.4 \%)$ & $21(91.3 \%)$ \\
& $1(5.6 \%)$ & $2(8.7 \%)$
\end{tabular}

Flap application

VP shunt

Simultaneous Shunting
$9(50 \%)$

$5(\% 27.7)$

$4(\% 22.2)$
$13(56.5 \%)$

$8(\% 34.8)$

$5(\% 21.7)$

\section{Delayed Shunting}

\begin{tabular}{|lll|}
\hline Patients with surgical complications & $8(44.4 \%)$ & $7(30.4 \%)$ \\
\hline Return to operation room in 30 days & $5(27.7 \%)$ & $6(26.1 \%)$
\end{tabular}

$V P$ Ventriculoperitoneal

Total complications, additional anomalies, localization of meningomyelocele and neurological status of the study population were summarized in Table 3. Echocardiography, cranial and abdominal USG were performed preoperatively for every patient in order to detect accompanying anomalies. Patients with hydrocephalus detected by cranial ultrasonography were evaluated by cerebral tomography to confirm the diagnosis. Hydrocephalus was the most common anomaly accompanying MMC, seen in 22 (53.7\%) 
patients. The second most common accompanying anomaly was pes equinovarus in 20 (48.8\%) patients. Chiari 2 malformation was detected in 5 patients (12.2\%). The most common localization was the lumbosacral region (34.1\%) and the lumbar region (26.8\%). After MMC repair surgery, minor dehiscence was observed in 6 (14.6\%), major dehiscence in 3 (7.3\%), CSF leakage in 3 (7.3\%), meningitis and ventriculitis in $3(7.3 \%)$, and local infection in $2(4.8 \%)$ patients (Table 3 ).

Table 3. Total complication, additional anomalies, localization of meningomyelocele and neurological status of the study population 


\begin{tabular}{lllll} 
& & $\begin{array}{c}\text { Total } \\
(\mathbf{n}, \%)\end{array}$ & $\begin{array}{l}\text { Early } \\
(\mathbf{n}, \%)\end{array}$ & $\begin{array}{l}\text { Late } \\
(\mathrm{n}, \%)\end{array}$ \\
\hline Total Complications & $6(14.6 \%)$ & $2(11.1 \%)$ & $4(17.4 \%)$ \\
\cline { 2 - 5 } & Minor dehiscence & $3(7.3 \%)$ & $2(11.1 \%)$ & $1(4.3 \%)$ \\
\hline Major dehiscence & $3(7.3 \%)$ & $2(11.1 \%)$ & $1(4.3 \%)$ \\
\hline Meningitis and ventriculitis & $3(7.3 \%)$ & $2(11.1 \%)$ & $1(4.3 \%)$ \\
\hline & & & $1(4.3 \%)$
\end{tabular}

Accompanying Anomaly Hydrocephalus

$22(53.7 \%) \quad 9(50 \%) \quad 13(56.5 \%)$

Pes equinovarus

$20(48.8 \%) \quad 10(55.6 \%) \quad 10(43.5 \%)$

Chiari 2 malformation

$5(12.2 \%) \quad 2(11.1 \%) \quad 3(13.0 \%)$

Hydronephrosis

$3(7.3 \%)$

$1(5.6 \%)$

$2(8.7 \%)$

Ventricular septal defect $\quad 3(7.3 \%) \quad 3(16.7 \%)$

Renal Agenesis

$1(2.4 \%) \quad 1(5.6 \%)$

Anal atresia

$1(2.4 \%)$

$1(4.3 \%)$

Thoracic

$7(17 \%)$

$3(16.6 \%)$

$4(17.4 \%)$ 


\begin{tabular}{lccc} 
Thoracolumbar & $9(21.9 \%)$ & $4(22.2 \%)$ & $5(21.7 \%)$ \\
\hline Lumbar & $11(26.8 \%)$ & $6(33.3 \%)$ & $5(21.7 \%)$ \\
\hline Lumbosacral & $14(34.1 \%)$ & $5(27.7 \%)$ & $9(39.1 \%)$
\end{tabular}

Neurologic Status

Norma

$5(12.2 \%) \quad 3(16.7 \%)$

$2(8.7 \%)$

Paraparesis

$17(41.5 \%) \quad 6(33.3 \%)$

$11(47.8 \%)$

Paraplegic

$19(46.3 \%) \quad 9(50.0 \%)$

$10(43.5 \%)$

CSF Cerebrospinal fluid

No patients died in the study. None of the mothers had received folic acid replacement from the preconceptional period; only 22 patients had folic acid supplementation from the mid-first trimester. There was no change in lower extremity motor strength in the preoperative and postoperative neurological examinations between the two groups. After primary repair surgery, VP shunt placement was performed in 9 patients and reoperation was performed due to complications in 2 patients. A total of 10 (24.4\%) patients were referred to our hospital after being born in an external center. All patients $(n=5$, $12.2 \%)$ who had ruptured MMC sac in the preoperative period were in the early surgery group.

\section{Discussion}

Neural tube defects are the most common congenital anomaly of the central nervous system [1]. Meningomyelocele is the most common anomaly among NTD defects. While the incidence of meningomyelocele in developed countries is gradually decreasing, it is still an important health problem in developing countries. Postnatal management of $\mathrm{MMC}$ is discussed with parents of patients who have antenatal diagnosis in developed countries and $60-70 \%$ of them decide to terminate pregnancy [13]. Only $22 \%$ of our patients had antenatal diagnosis. None of the families diagnosed with antenatal diagnosis approved the decision of termination of pregnancy, due to anti-abortion socio-cultural and religious reasons. 
The current approach to the timing of MMC surgical repair is in favor of early surgery $[14,15]$. However, it is necessary to have an appropriate time interval to obtain comprehensive information about the patient's clinical condition and to plan surgical reconstruction adequately. Prenatal diagnosis, detailed examination and delivery of MMC patients in centers where early surgery can be performed is ideal. Approximately one quarter of our patients (10 patients) were born in an external center and were referred to our hospital.

Cases with hydrocephalus constitute approximately $85-90 \%$ of patients with MMC $[16,17]$. In our study, the number of MM patients who had accompanying hydrocephalus was 24 (58.5\%). In 15\% of cases accompanied by hydrocephalus at birth, signs of increased intracranial pressure (vomiting, dehiscence, sun-setting eyes, stretched fontanel) or brain stem dysfunction (apnea, sucking-swallowing disorder) may be observed [18]. Chiari II malformation is common, especially in patients with brain stem dysfunction and urgent treatment is required. In patients with NTD, VPS (ventriculoperitoneal shunt) is needed to prevent neurocognitive and motor dysfunction caused by the accompanying Chiari II malformation and hydrocephalus [19]. Therefore, at least $80 \%$ of patients with NTD require VPS [2]. The timing of treatment of hydrocephalus accompanying MMC is still controversial due to factors such as infection, intellectual development and shunt dysfunction. Early shunt placement has been reported to improve rapid intracranial pressure in the presence of severe hydrocephalus and to improve wound healing faster in the MMC repaired area, also shortening hospital stay, preventing CSF leakage and protecting the brain from progressive ventricular dilatation 16,20 ]. It is contemplated that shunt placement time may affect the rate of shunt infection, and that shunt placement reverses the flow of cerebrospinal fluid and allows fluid from the lumbar region to travel to the ventricles to facilitate infection. Therefore, infective complications were observed more frequently in patients with simultaneous shunt placement with MMC repair than those with late shunt placement [21]. Oktem et al. reported that VP shunt placement after MMC repair reduces wound infection, CSF leakage, and shunt infection in patients, in their study comparing VP shunt placement in the same and different sessions with MMC repair [22]. The approach to treating hydrocephalus days or weeks after MMC surgical repair is more often preferred. The number of patients requiring VPS placement in our study was 22 (53.7\%). According to the literature, our hydrocephalus rate was lower. In our study, 13 (31.7\%) patients had simultaneous VPS and 9 (21.9\%) patients had late VPS; there was no statistical difference between the groups in terms of the number of patients requiring VPS. Early VPS placement was performed in patients with symptoms of symptomatic hydrocephalus and brain stem dysfunction (sucking swallowing disorder, apnea).

In our study, of the patients who developed surgical complications, 8 (44.4\%) patients were in the early surgery group and $7(30.4 \%)$ patients were in the late surgery group. CNS infections (ventriculitis and meningitis) were observed in $3(7.3 \%)$ patients. In the literature, ventriculitis and meningitis independent of shunt infection have been reported as $4-12.5 \%$ in $M M C$ patients $[23,24,25]$. Ventriculitis and meningitis complications were observed in $7.3 \%$ of our patients.

The most common site of MMC is lumbar with $60-70 \%[25,26]$. In our study, $26.8 \%$ of the localizations where $\mathrm{MMC}$ was seen were in the lumbar region, and together with the lumbosacral region, it made up 
$60.9 \%$ of the cases.

The debate about the optimal time for $\mathrm{MMC}$ repair has gained a new dimension with the increasing experience of intrauterine surgery. Since 1997, experimental procedures for prenatal repair of MMC have begun to increase the experience of fetal surgery [28. Approximately $80 \%$ of NTDs require VPS in the postnatal period in order to prevent the destruction of hydrocephalus on brain tissue and to prevent deterioration of neurocognitive development [21]. Prenatal surgery provides significant improvement in hindbrain herniation and reduces the risk of Chiari II malformation. In initial studies, prenatal surgery was shown to reduce the need for VPS by $50 \%$ in the first year [29]. Tulipan et al. showed that they reduced the risk of hydrocephalus significantly (85.7\% control vs. $54.8 \%$ study group) with prenatal surgery performed at 25 weeks of gestation or less, when compared to the traditional method [30]. The safety and efficacy of intrauterine surgery were evaluated in a randomized controlled MOMS (Management of Myelomeningocele Study) study comparing prenatal and postnatal surgery. In this large multicenter study, intrauterine surgery reduced shunt requirement and improved motor outcomes at 30 months but was associated with maternal and fetal risks like preterm delivery and uterine dehiscence at delivery [31]. Intrauterine MMC surgery continues to be performed in experienced centers. Postnatal traditional surgery is widely performed all over the world.

Early aggressive treatment approach in postnatal MMC surgery reduces early morbidity and mortality rates [32]. Oncel et al. demonstrated that early surgery (<5 days) shortened hospital stay and antibiotic treatment time and reduced complication rates [14]. In the long term, it is reported that cognitive functions are better, need for long-term care and incidence of urinary incontinence are reduced and it positively affects neurogenic bladder prognosis and thus urinary tract function [33,34,35]. Preoperative rupture of MMC, postoperative dehiscence, and incidence of neurodevelopmental retardation 1 year after delivery showed improved outcome after immediate surgical intervention after birth (mean time of surgery after birth 1 h $30 \mathrm{~min}$ ) [15]. In our study, although there was a shorter duration of hospital stay and antibiotic treatment in the early surgery group, there was no statistical difference. The number of prenatally diagnosed patients in the early surgery group was higher than those in the late surgery group. There were no significant differences between the groups in terms of the number of patients who developed surgical complications and total complications. In our study, we believe the fact that all patients who developed preop MMC sac rupture being in the early surgery group (<3 days) was important in terms of not showing significant difference between the early and late surgery groups. In addition, low hydrocephalus rate in our cases is one of the factors that cause no difference in prognosis. The fact that the number of patients who were reoperated except for VPS placement after primary surgery is low in both groups is the reason that there is no difference in prognosis.

Our study had many limitations. Most importantly, the number of patients included in the study was limited, it was retrospective, and a single-center study. The inclusion of a single center in the study was an advantage as perioperative interventions and treatments were standard. In our study, we were able to evaluate short-term results. One of the major limitations of the study was the lack of evaluation of the 
long-term outcome of a clinical condition, especially for MMC which is a major cause of lifelong morbidity.

In conclusion, surgical timing of MMC remains important considering the morbidity risks. National policy on prenatal follow-up of pregnancy and folic acid supplementation should be formulated and implemented to prevent NTD development. In countries where MMC is frequently observed, intrauterine surgery is not yet widespread. We believe that in addition to postnatal surgery timing, preoperative sac rupture, VPS placement time and accompanying anomalies (such as hydrocephalus) are the predictors of MMC prognosis.

\section{Abbreviations}

MMC: Meningomyelocele

VPS: Ventriculoperitoneal shunt

CSF: Cerebrospinal fluid

NTD: Neural tube defect

VSD: Ventricular septal defect

USG: ultrasonography

CT: computarised tomography

VP: Ventriculoperitoneal

SPSS: Statistical Package for the Social Sciences

CS: Cesarian section

CNS: Central nerve system

MOMS: Management of myelomeningocele study

\section{Declarations}

\section{Acknowledgements}

We are grateful to Ilker Unal, PhD, Department of Biostatistics, Cukurova University, for his help in the statistical analysis.

\section{Author's Contribtions}


Dr. M. Kurthan MERT: Designed the study, collected the data, performed statistical analyses, drafted the initial manuscript and approved the final manuscript as submitted. Dr. A. İhsan ÖKTEN: Coordinated and supervised data collection, critically reviewed the manuscript and approved the final manuscript as submitted.

\section{Funding}

The authors declared that this study has received no financial support.

\section{Availability of data and materials}

Please contact author for data requests.

\section{Ethics approval and consent to participate}

Ethical approval for this study was received from the Adana City Training and Research Hospital Clinical Research Ethics Committee (August 2019, 543).

\section{Consent for publication}

Not applicable.

\section{Competing interests}

No conflict of interest was declared by the authors.

\section{References}

1. Back SA. Congenital malformations of the central nervous system. In: Taeusch HW, Ballard RA, Gleason CA. (eds). Avery's Diseases of the Newborn. 8th ed. Philadelphia: Elsevier 2005; 938- 959.

2. Bowman RM, Boshnjaku V, McLone DG: The changing incidence of myelomeningocele and its impact on pediatric neurosurgery: a review from the Children's Memorial Hospital. Childs Nerv Syst 2009; 25: 801-806.

3. Chakraborty A, Crimmins D, Hayward R, Thompson D: Toward reducing shunt placement rates in patients with myelomeningocele. J Neurosurg Pediatr 2008; 1: 361-365.

4. Phillips BC, Gelsomino M, Pownall AL, Ocal E, Spencer HJ, O'Brien MS, et al: Predictors of the need for cerebrospinal fluid diversion in patients with myelomeningocele. J Neurosurg Pediatr 2014; 14 : 167-172.

5. Boulet SL, Yang Q, Mai C, et al. Trends in the post fortification prevalence of spina bifida and anencephaly in the United States. Birth Defects Res A Clin Mol Teratol 2008; 82: 527-532.

6. Frey L, Hauser WA : Epidemiology of neural tube defects. Epilepsia 2003; 44 Suppl 3: 4-13. 
7. Tunçbilek E, Boduroğlu K, AlikaŞifoğlu M : Neural tube defects in Turkey : prevalence, distribution and risk factors. Turk J Pediatr 1999; 41: 299-305.

8. Onrat ST, Seyman H, Konuk M : Incidence of neural tube defects in Afyonkarahisar, Western Turkey. Genet Mol Res 2009; 8: 154-61.

9. Yerby MS. Management issues for women with epilepsy: neural tube defects and folic acid supplementation. Neurology 2003; 61: 23-26.

10. Martínez de Villarreal LE, Arredondo P, Hernández R, Villarreal JZ. Weekly administration of folic acid and epidemiology of neural tube defects. Matern Child Health J 2006; 10: 397-401.

11. Essien FB, Wannberg SL. Methionine but not folinic acid or vitamin B-12 alters the frequency of neural tube defects in Axd mutant mice. J Nutr 1993; 123: 27-34

12. Zeyrek D, Soran M, Cakmak A, Kocyigit A, Iscan A. Serum Copper and Zinc Levels in Mothers and Cord Blood of their Newborn Infants with Neural Tube Defects: A Case-control Study. Indian Pediatr 2009; 46: 675-80.

13. Prenatal screening, diagnosis, and pregnancy management of fetal neural tube defects. Wilson RD, Audibert F, Brock JA et al. J Obstet Gynaecol Can 2014; 36: 927-39.

14. Oncel MY, Ozdemir R, Kahilogulları G, Yurttutan S, Erdeve O, Dilmen U. The effect of surgery time on prognosis in newborns with meningomyelocele. J Korean Neurosurg Soc. 2012;51: 359-62.

15. Pinto FC, Matushita H, Furlan AL, Alho EJ, Goldenberg DC, Bunduki V, Krebs VL, Teixeira MJ. Surgical treatment of myelomeningocele carried out at 'time zero' immediately after birth. Pediatr Neurosurg. 2009; 45: 114-18.

16. Miller PD, Pollack IF, Pang D, Albright AL Comparison of simultaneous versus delayed ventriculoperitoneal shunt insertion in children undergoing myelomeningocele repair. J Child Neurol. 1996; 11: 370-72.

17. Pinar $\mathrm{H}$, Tatevosyants $\mathrm{N}$, Singer DB : Central nervous system malformations in a perinatal/neonatal autopsy series. Pediatr Dev Pathol. 1998; 1: 42-48.

18. Tulipan N, Bruner JP, Hernanz-Schulman M, Lowe LH, Walsh WF, Nickolaus D, Oakes WJ: Effect of intrauterine myelomeningocele repair on central nervous system structure and function. Pediatr Neurosurg 1999; 31: 183-88.

19. Tulipan N, Hernanz-Schulman M, Bruner JP: Reduced hindbrain herniation after intrauterine myelomeningocele repair: a report of four cases. Pediatr Neurosurg 1998; 29: 274-78.

20. Chadduck WM, Reding DL Experience with simultaneous ventriculo-peritoneal shunt placement and myelomeningocele repair. J Pediatr Surg. 1988; 23: 913-16.

21. Caldarelli M, Di Rocco C, La Marca F. Shunt complications in the first postoperative year in children with meningomyelocele. Childs Nerv Syst. 1996; 12: 748-54.

22. Oktem Si, Menkü A, Ozdemir A. When should ventriculoperitoneal shunt placement be performed in cases with myelomeningocele and hydrocephalus? Turkish Neurosurgery 2008; 18: 387-91. 
23. Shehu BB, Ameh EA, Ismail NJ: Spina bifida cystica: Selective management in Zaria, Nigeria. Ann Trop Paediatr. 2000; 20: 239-42.

24. Ammirati M, Raimondi AJ: Cerebrospinal fluid shunt infections in children. Astudy on the relationship between the etiology of hydrocephalus, age at the time of shunt placement, and infection rate. Childs Nerv Syst. 1987; 3: 106-9.

25. Brau RH, Rodriguez R, Ramirez MV, Gonzalez R, Martinez V: Experience in the management of myelomeningocele in Puerto Rico. J Neurosurg. 1990; 72: 726-31.

26. Liptak GS, Dosa NP : Myelomeningocele. Pediatr Rev ; 31: 443-50.

27. Padmanabhan R : Etiology, pathogenesis and prevention of neural tube defects. Congenit Anom (Kyoto) 2006; 46: 55-67.

28. Tulipan N, Hernanz-Schulman M, Bruner JP: Reduced hindbrain herniation after intrauterine myelomeningocele repair: a report of four cases. Pediatr Neurosurg 1998; 29: 274-78.

29. Bruner JP, Tulipan N, Paschall RL, Boehm FH, Walsh WF, Silva SR, Hernanz-Schulman M, Lowe LH, Reed GW: Fetal surgery for myelomeningocele and the incidence of shunt-dependent hydrocephalus. JAMA 1999; 282: 1819-825

30. Tulipan N, Sutton LN, Bruner JP, Cohen BM, Johnson M, Adzick NS: The effect of intrauterine myelomeningocele repair on the incidence of shunt-dependent hydrocephalus. Pediatr Neurosurg 2003; 38: 27-33.

31. Adzick NS, Thom EA, Spong CY, Brock JW 3rd, Burrows PK, Johnson MP, Howell LJ, Farrell JA, Dabrowiak ME, Sutton LN, Gupta N, Tulipan NB, D'Alton ME, Farmer DL; MOMS Investigators. A randomized trial of prenatal versus postnatal repair of myelomeningocele. N Engl J Med 2011;364: 993-1004.

32. Adzick NS, Walsh DS. Myelomeningocele : prenatal diagnosis, pathophysiology and management. Semin Pediatr Surg 2003; 12: 168-74.

33. Hunt GM, Holmes AE. Some factors relating to intelligence in treated children with spina bifida cystica. Dev Med Child Neurol Suppl 1975; 35: 65-70.

34. Idowu OE, Apemiye RA. Outcome of myelomeningocoele repair in sub-Saharan Africa: the Nigerian experience. Acta Neurochir (Wien) 2008; 150: 911-13.

35. Tarcan T, Onol FF, llker Y, Alpay H, Simşek F, Ozek M. The timing of primary neurosurgical repair significantly affects neurogenic bladder prognosis in children with myelomeningocele. J Urol. 2006; 176: 1161-165. 